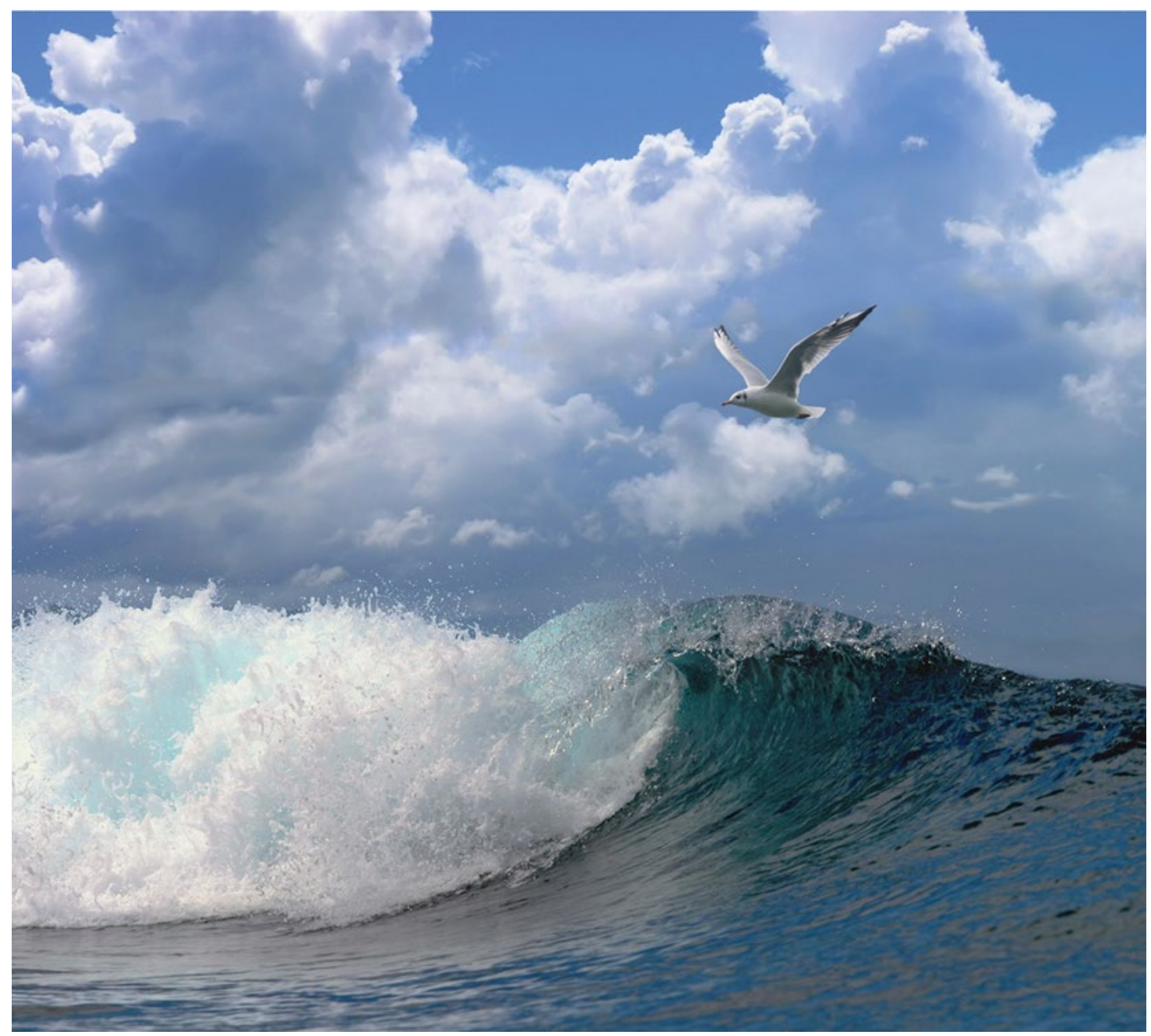

Silver eel mortality during downstream migration in the Meuse: comparing telemetry study 2010-2012 to 2002-2006 


\section{Silver eel mortality during downstream migration in the Meuse: comparing telemetry study 2010-2012 to 2002- 2006}


Keywords: Anguilla anguilla, migration, Meuse, telemetry, mortality

Client: $\quad$ Ministerie van Landbouw, Natuur en Voedselkwaliteit Attn.: Mr. Laurent Gorissen

Bezuidenhoutseweg 73

2594 AC DEN HAAG

BAS Code: WOT-05-001-007.

This report can be downloaded for free from https://doi.org/10.18174/505630.

Wageningen Marine Research provides no printed copies of reports.

Wageningen Marine Research is ISO 9001:2015 certified.

\section{(C) Wageningen Marine Research}

Wageningen Marine Research, an institute Wageningen Marine Research accepts no liability for consequential damage, nor within the legal entity Stichting for damage resulting from applications of the results of work or other data Wageningen Research (a foundation under obtained from Wageningen Marine Research. Client indemnifies Wageningen Dutch private law) represented by Dr. Marine Research from claims of third parties in connection with this application. M.C.Th. Scholten, Managing Director All rights reserved. No part of this publication may be reproduced and / or

KvK nr. 09098104, published, photocopied or used in any other way without the written permission WMR BTW nr. NL 8113.83.696.B16.

Code BIC/SWIFT address: RABONL2U IBAN code: NL 73 RABO 0373599285 


\section{Contents}

$\begin{array}{lr}\text { Summary } & 4\end{array}$

$1 \quad$ Introduction $\quad 5$

$2 \quad$ Mortality and behavioural patterns using telemetry 6

$2.1 \quad$ Direct and delayed mortality estimations 6

$3 \quad$ Material and methods $\quad 7$

$\begin{array}{lll}3.1 & \text { Study area and telemetry } & 7\end{array}$

3.2 Analysis of telemetry dataset $\quad 9$

3.2.1 HPS, weir, fishway 9

3.2.2 Ship locks $\quad 9$

3.2.3 Mortality estimation protocol 9

$\begin{array}{ll}\text { 3.2.4 Delayed mortality estimations } & 10\end{array}$

$4 \quad$ Results: mortality estimations $r$

4.1 Migrating batch and timing $\quad 11$

4.2 Disappearances of eel during downstream descend 11

$\begin{array}{lll}4.3 & \text { HPS mortality estimations } & 13\end{array}$

4.3.1 HPS-Mortality according to protocol cf 2002 and $2004 \quad 13$

4.3.2 New mortality estimations 13

$\begin{array}{lll}4.4 & \text { Indirect or delayed mortality } & 13\end{array}$

$5 \quad$ Discussion and conclusions $\quad 15$

5.1 HPS-mortality compared to mortality before fisheries ban? 15

5.2 What is the delayed and direct mortality estimation of the migration batch? 15

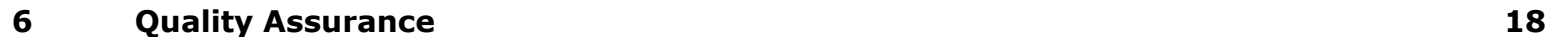

$\begin{array}{lr}\text { References } & 19\end{array}$

$\begin{array}{lr}\text { Justification } & 20\end{array}$ 


\section{Summary}

During the descend to sea, silver eel face different hazards causing migration delay or mortality (e.g. dams, hydropower stations (HPS), weirs, ship locks, fisheries, predation). In 2010 fisheries was closed from September - November 30th and from April 1th 2011 the commercial eel fisheries in the river Meuse was closed for a undetermined period, due to dioxin pollution. To compare general mortality percentages with earlier studies (2002 and 2004), additional telemetry studies were carried out in 2010 and 2011. Compared to earlier studies more detection stations were used to estimate the mortality of the migration silver eel. This report attempts to answer two research questions:

1) Did the closure of the fisheries starting in 2010 result in a lower mortality rate for downstream migrating silver eel in the Meuse compared to previous studies in 2002-2006? 2)What is the delayed and direct Hydro power station (HPS) mortality for migrating silver eel in the Meuse during 2010-2012?

In 2010 a batch of 150 female silver eel with surgically implanted transponders was released in the river Meuse and they could be followed with an array of detection stations of the Nedap Trail ${ }^{\mathrm{TM}}$ System. From the detection data mortality estimations were obtained. The present report is restricted to analysing migration routes and mortality estimations for the batch released in 2010.

In accordance with the methodology used in 2002 ( $16-26 \%$ mortality) and 2004 ( $25-34 \%$ mortality) there was no big difference found in mortality estimations in 2010 (13-26\% mortality). A comparison between the methodology used in previous studies ( $13-26 \%$ mortality) and new mortality estimations using more detection stations (22-25\%) suggests that a more precise mortality estimation must be found in the upper limits of the mortality ranges derived from previous studies. Based on telemetry we found a minimum percentage of delayed and direct mortality of at least $20 \%$ of the migrating batch (121 eel). This percentage was corrected for other factors causing mortality (e.g. natural mortality, disease, predation etc.). 


\section{Introduction}

European eel (Anguilla anguilla) has been in decline for several decades (ICES 2018). An important factor contributing to this decline is the silver eel mortality during migration to the sea (e.g. dams, hydropower stations (HPS), weirs, ship locks, fisheries, predation). During the descend to sea, migrating silver eel face different hazards causing migration delay or mortality.

Telemetry studies carried out during 2002-2006 were used to assess mortality rates for hydropower stations and fisheries and yielded insight in behavioural patterns near barriers and during downstream descend (Winter et al. 2006, Jansen et al. 2007, Winter et al. 2007). Since then, management measures have been made for fisheries in the river Meuse. In 2010 there was a closed period from September November 30th and since April 1th 2011 the commercial eel fisheries in the river Meuse was totally closed for a undetermined period, due to dioxin pollution. To compare mortality percentages with earlier studies (2002 and 2004), an additional telemetry studies were carried out in 2010. Specific HPS mortality percentages may differ from year to year due to environmental circumstances (e.g. water discharge) or management changes. In 2010 a batch of 150 female silver eel with implanted transponders was released in the river Meuse and they could be followed with an array of detection stations of the Nedap Trail ${ }^{\mathrm{TM}}$ System (Breukelaar et al. 1998). From the detection data mortality estimations were obtained.

The main questions were:

- What are the delayed and direct mortality estimates for downstream migrating silver eel in the Meuse during 2010-2012?

- $\quad$ Did the measures to close fisheries starting in 2010 result in a lower mortality rate for migrating silver eel in the Meuse compared to 2002-2006? 


\section{Mortality and behavioural patterns using telemetry}

\subsection{Direct and delayed mortality estimations}

Direct and delayed eel mortality estimations in the river Meuse have been studied in several studies (Bruijs et al. 2003, Winter et al. 2006, Jansen et al. 2007, Winter et al. 2007). Telemetry detection stations detect only active fish, but can also give insight in mortality estimations by non-detected fish. If an individual migrating fish shows no activity after a series of detections, there are several possible explanations for their inactivity (Winter et al. 2006). One of the explanations is mortality after migration through a HPS. This mortality caused by passing a HPS can be divided in two categories:

1) Direct mortality

a. Disappearance directly upstream the HPS. The eel died in the turbines of the HPS and the transponder was broken and / or remained in the HPS.

b. Disappearance directly downstream the HPS. The silver eel migrated through the HPS and was lethally injured by the turbines and died in or directly after passage through the HPS. There was a detection directly downstream the HPS, but there was no detection at the first detection station further downstream covering river bed.

\section{2) Delayed mortality}

a. Delayed mortality is defined as mortality due to passage through a HPS causing lethal external and /or internal wounds which are not directly fatal. The silver eel dies further downstream or after several days.

Bruijs et al. (2003) did a study based on catches behind the HPS. They found that $24 \%(n=404)$ of the silver eel that had passed the HPS had lethal injuries. Another study found a $12-35 \%$ injury rate depending on the discharge through the turbine and length of the eel (Hadderingh and Bakker 1998).

With detection stations up- and downstream the HPS-weir complex, the route of an individual eel can be assessed. If an eel went through the HPS and disappeared in one of the river sections downstream the HPS, the eel may have died due to delayed mortality causes (i.e. wounds or broken spine etc.). There is also a group of eel that did not pass the HPS, but passed an alternative route. The mortality of the population that disappeared in the river sections after passing the HPS should be corrected for the group of eel that passed an alternative route. This latter group was exposed to mortality causes other than mortality causes of the turbines (e.g. natural mortality, predation, fisheries etc.). 


\section{Material and methods}

\subsection{Study area and telemetry}

The river Meuse, originating in France and flowing through Belgium and the Netherlands, has a total length of $935 \mathrm{~km}$, a catchment area of $36,000 \mathrm{~km}^{3}$, and a mean discharge of $230 \mathrm{~m}^{3} / \mathrm{s}$. The river is characterized by short peak flows following rainfall (Winter et al. 2006). Several detection stations are located (Figure 1 and Table 1) to follow individual fish with an implanted transponder. The river has two hydropower stations located at Linne (HPS I) and Alphen / Lith (HPS II). Both stations have a fishway, a weir and ship lock complexes in their vicinity.

Eel were caught by a local professional fisherman with fykenets during September and October 2010 in the River Meusse at Ohé en Laak and stored in aerated basins for up to several days. Only eel with completely silvery white ventral side were used, rejecting individuals with yellow of partly yellow ventral sides (no migrating eel). Three batches of in total 150 eel were surgically implanted with a transponder and released on September $14(n=47)$ and $23(n=75)$ and October $5(n=28)$ in 2010. The eel in 2010 ranged in length from $53.2-100 \mathrm{~cm}$ (mean $83 \mathrm{~cm}$ ), weighing $660-1879 \mathrm{~g}$ (mean $1144 \mathrm{~g}$ ). All individual eel were assumed to be females, since males do not grow that large (Dekker 2000).

Compared to the studies carried out in 2002 and 2004 (Winter et al. 2006, Jansen et al. 2007, Winter et al. 2007), the number of detection stations was extended from 18 to 34 stations (Table 1). Each of these detection stations contained three parallel antenna cables on the river bottom, mainly located near barriers (weir or hydro power stations) in the river. The stations send out interrogation signals every $4 \mathrm{~s}$, which activate each transponder that passes. The transponder then sends out a unique code, which is received by the station. If a silver eel was continuously within a detection range, it sends out a signal every 2 minutes. Lifetime of these transponders is guaranteed for 2 years, when the total number of detections does not exceed 1000. Other studies using Nedap-transponders showed that lifetime of over 4 years and over 3000 detections are feasible (Winter and Fredrich 2003). At HPS I (Figure 1) there are four stations upstream and two directly downstream of the HPS - weir complex. At HPS II (Figure 1) there are two stations upstream and two downstream of the HPS - weir complex. 


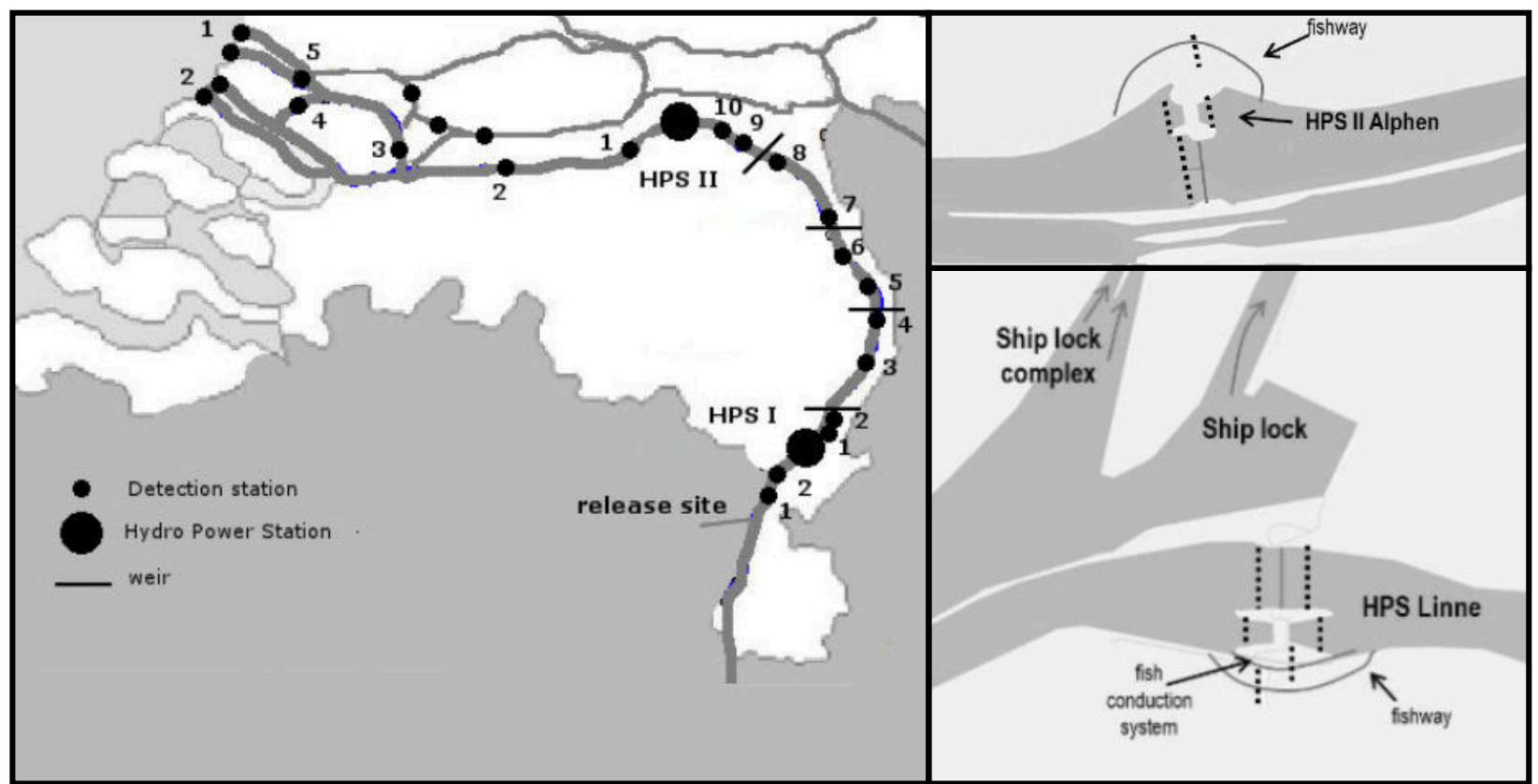

Figure 1. River Meuse with several detection stations (not all individual detection stations are indicated). Numbers are corresponding with Table 1.

Table 1. River section numbering for the river Meuse with detection stations and distance to the sea $(\mathrm{km})$. Also alternative route (fishway or ship lock) presence is indicated. HPS = Hydro Power Station.

\begin{tabular}{|c|c|c|c|c|c|c|}
\hline $\begin{array}{c}\text { River } \\
\text { section }\end{array}$ & Dutch name & $\begin{array}{c}\text { distance to } \\
\text { sea }(\mathbf{k m}) \\
\end{array}$ & fishway & ship lock & weir & $\begin{array}{c}\text { Detection } \\
\text { stations (n) }\end{array}$ \\
\hline 1 & $\begin{array}{c}\text { Ohé Laak (cath and } \\
\text { release site) }\end{array}$ & 257 & \multirow{4}{*}{ yes } & \multirow{4}{*}{ yes } & \multirow{4}{*}{ yes } & \\
\hline 2 & Stevensweert & 262 & & & & 1 \\
\hline HPS I & Linne & 254 & & & & 6 \\
\hline 1 & Linne Dorp & 245 & & & & 1 \\
\hline 2 & Roermond & 241 & \multirow[t]{2}{*}{ yes } & \multirow[t]{2}{*}{ yes } & \multirow[t]{2}{*}{ Yes } & 2 \\
\hline 3 & Buggenum & 237 & & & & 1 \\
\hline 4 & Belfeld & 221 & \multirow[t]{3}{*}{ yes } & \multirow[t]{3}{*}{ yes } & \multirow[t]{3}{*}{ Yes } & 2 \\
\hline 5 & Steyl & 219 & & & & 1 \\
\hline 6 & Afferden & 178 & & & & 1 \\
\hline 7 & Sambeek & 177 & yes & yes & Yes & 2 \\
\hline 8 & Grave & 146 & \multirow[t]{3}{*}{ yes } & \multirow[t]{3}{*}{ yes } & \multirow[t]{3}{*}{ Yes } & 2 \\
\hline 9 & Balgoij & 138 & & & & 1 \\
\hline 10 & Megen & 131 & & & & 1 \\
\hline HPS II & Alphen & 124 & \multirow[t]{9}{*}{ yes } & \multirow[t]{9}{*}{ yes } & \multirow[t]{9}{*}{ Yes } & 4 \\
\hline 1 & Alphen Dorp & 124 & & & & 1 \\
\hline 2 & Capelse Veer & 84 & & & & 1 \\
\hline 3 & Dortse Kill & 46 & & & & 1 \\
\hline 4 & Spui & 18 & & & & 1 \\
\hline 5 & Spijkenisse & 22 & & & & 1 \\
\hline \multicolumn{4}{|l|}{ Sea } & & & \\
\hline 1 & Nieuwe Waterweg & 0 & & & & 2 \\
\hline 2 & Haringvliet & 0 & & & & 2 \\
\hline
\end{tabular}




\subsection{Analysis of telemetry dataset}

The telemetry dataset was analysed, based on the assumptions in the following text.

\subsubsection{HPS, weir, fishway}

In accordance to (Winter et al. 2006), surgically implanted eel that were detected at HPSI (Figure 1), or further downstream, were classified as migrating eel. It was assumed that if an eel was detected upstream the HPS and subsequently directly downstream the HPS, it had passed through the turbines of the HPS. This was done similarly for the weir. In some cases only an upstream detection was present from the weir and /or HPS and no detection directly downstream the complex at the HPS or the weir, but there were detections further downstream. If there was no reason to assume that this particular eel did migrate through the ship locks or the fishway, the last upstream detection at the weir or HPS was taken as migration route.

\subsubsection{Ship locks}

It was assumed that eel could migrate through the ship locks at all times, if the locks were frequently used for either ship traffic or discharge management. Migrations through the ship lock complex in the vicinity of HPSI were estimated if detections at three station downstream the HPSI were missed ( 3 stations: at least one of the two directly downstream and stations Linne Dorp and Roermond, Figure 2). The same accounts for the smaller ship lock, but detections of at least two stations are being missed (at least one of the two directly downstream and station Linne Dorp). Misdetections could occur in one station, however it unlikely that a series of several misdetections of following stations occurred.
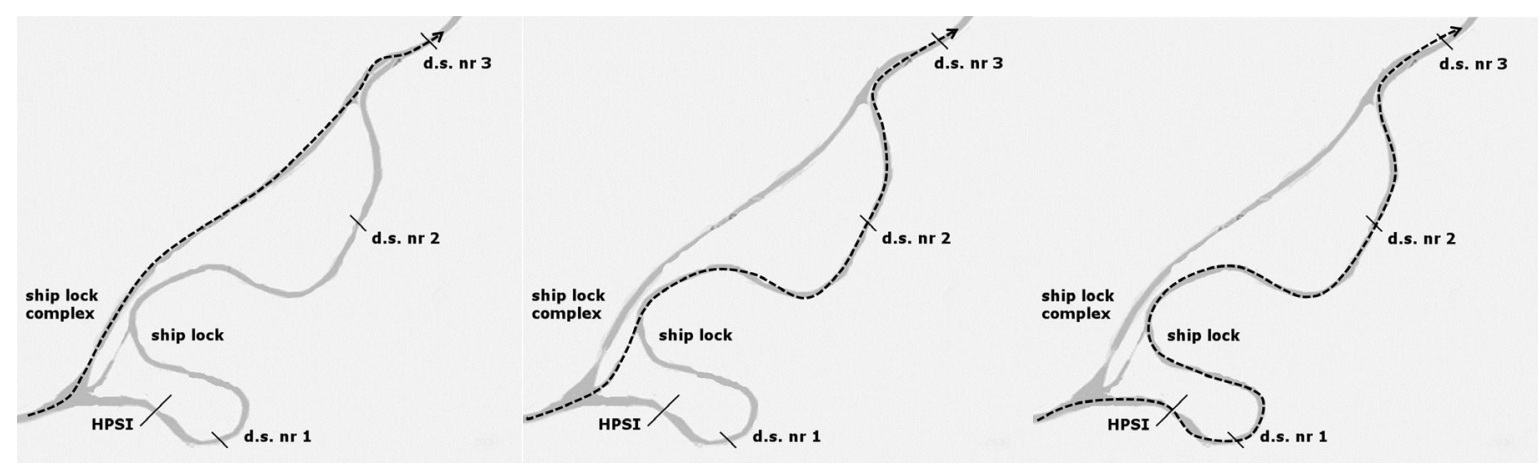

Figure 2 Different migration routes in the vicinity of the HPS. Left: the route through a sluice complex. Middle: the route through another smaller sluice. Right: the route through either the HPS or over the weir. d.s. = detections station

\subsubsection{Mortality estimation protocol}

The mortality estimation protocol used by Winter et al. (2006) and Jansen et al. (2007) was used and defined as follows: all eel detected at the entrance of the HPS could have been passed through the HPS. This assumption gives the maximum estimation of eel that passed through the HPS. According to Bruijs et al. (2003), 24\% of those eel will die due to the turbines (lethal injuries). However, many eel were considered to hesitate to pass through the HPS after reaching the entrance. Not all eel that were detected at the entrance will eventually pass through the turbines. A minimum estimation will be made based on hesitation or recurrence behaviour estimations. The maximum number of eel passing the turbines must be corrected for behavioural patterns in order to give a minimum estimation. The chosen correction factor, based on recurrence or hesitation behaviour, used for the minimum number of eel that passed through the HPS was $40 \%$ in 2002 and $25 \%$ in 2004. If eel were detected once or twice at the entrance of the HPS it was assumed that they passed the HPS immediately, however some eel were detected more than twice. This latter phenemomen was determined as hesitation or recurrence behaviour which determined the correction factor. For example, if 100 eel reached the entrance of the HPS of a migrating batch of 125 eel and $25 \%$ of the eel, which is 25 out of the 100 eel, was detected more than twice and is assumed to use an alternative route (i.e. the weir). The correction factor in this case is $25 \%$. In the minimum scenario, 75 eel $(100-25)$ of the eel will pass the turbines and $24 \%$ of those 75 eel will 
eventually die according to Bruijs et al. (2003). This means 75 times $0.24=18$ eel will die passing the HPS. The mortality rate is determined as follows:

Maximum HPS-mortality:

100 eelpassing the HPS $* 0.24=24$ eel

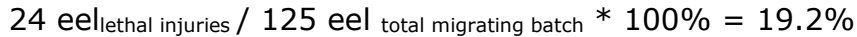

Minimum HPS-mortality:

Correction factor $=\%$ eel assumed taking another route

100 eel passingthe HPS $*\left(1-0.25_{\text {correction factor }}\right) * 0.24=18$ eel

18 eel lethal injuries / 125 eel total migrating batch $* 100 \%=14.4 \%$

A more precise estimation compared to Winter et al (2006) was done in 2010 because additional stations were installed and assumptions on migration routes could be ignored. In other words: no correction factor was needed since, contrary to 2002 and 2004, detection stations installed at the weir (upstream and downstream) and directly downstream the HPS allowed for precise route analyes. If no misdetection occurred, it could be precisely determined whether eel passed the HPS immediately or returned and passed over the weir. Also the time spent upstream the HPS - weir complex could be determined using the first detection upstream and the first detection downstream.

\subsubsection{Delayed mortality estimations}

With additional detection stations, which were installed before eel released in 2010 but after eel released in 2002 and 2004, it was possible to follow each individual eel that migrated through HPSI. Besides direct mortality estimations, also delayed mortality estimations could be made based on the telemetry data (dissappearance of eel in certain river sections). The sections upstream of HPSII were used to determine delayed mortality, because downstream of HPSII fewer consecutive detection stations are installed and multiple seaward routes are optional (Figure 1 and Table 1). To distinguish mortality caused by other factors than the HPS, the eel were divided into two groups:

group 1) eel that passed through the HPS and group 2) eel that used an alternative route (e.g. weir, ship lock, fishway etc). Group 2 functions as a reference for dissapperance caused by other factors than the turbines: e.g. natural mortality, predation mortality, mortality due to surgery, transmitter loss or failure, delayed migration etc. The difference between the two groups gives an estimation of delayed mortality. 


\section{$4 \quad$ Results: mortality estimations}

\subsection{Migrating batch and timing}

In total 121 silver eel started or continued their migration after surgically being implanted with a transponder. The data shows that silver eel migrated throughout the year but the majority started their migration approximately in the same period in autumn 2010 (Figure 3) and continued their migration continuously until arrival at sea. Only few individuals paused their migration to continue again in late spring and summer or postponed their migration to December 2011 or January 2012.

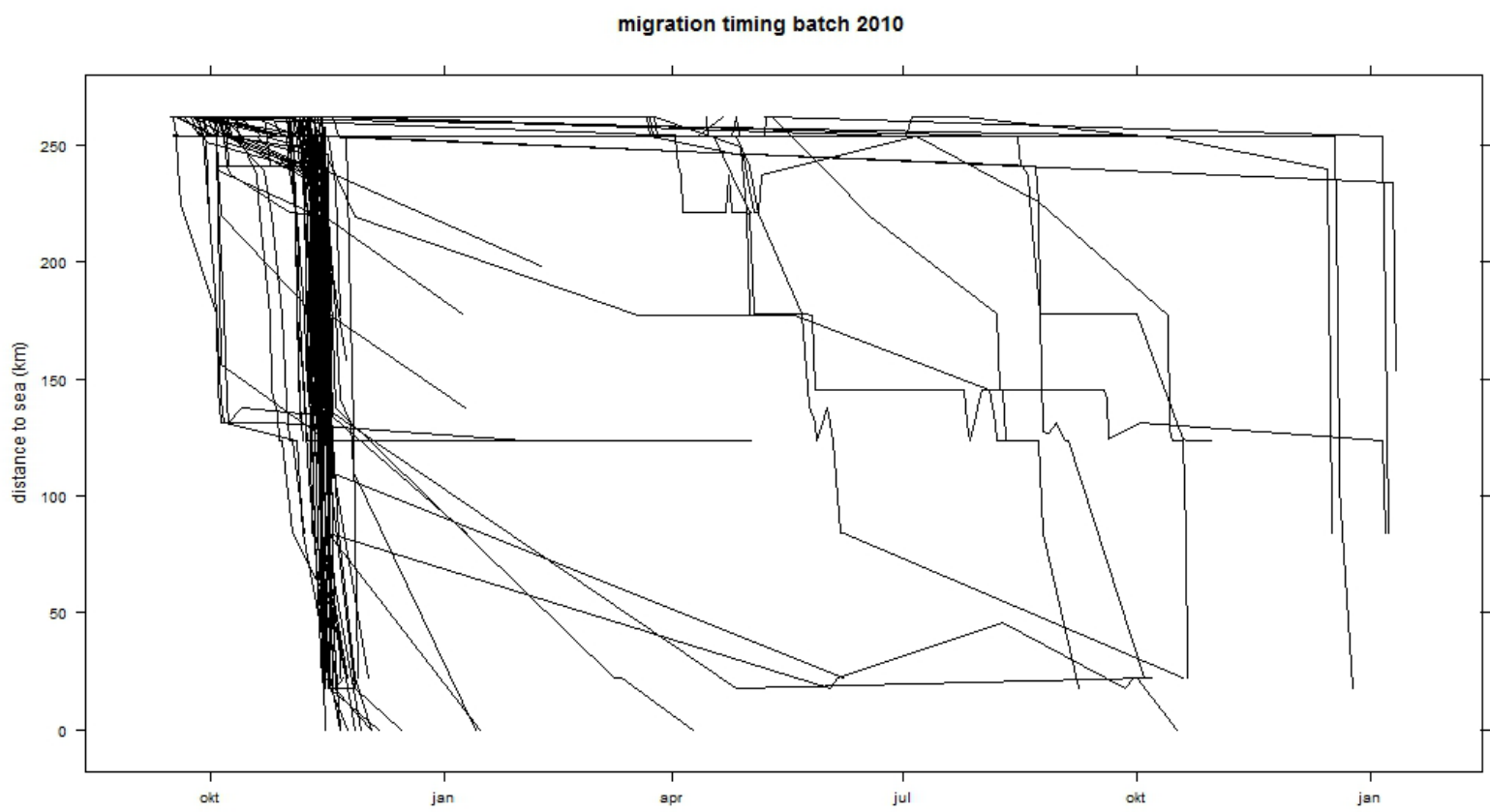

Figure 3 Timing of migration of the 121 silver eel released in the Meuse. The majority continued their migration route after surgically being implanted with Nedap transmitters. Some of the eel continued their migration in 2011 and in 2012.

\subsection{Disappearances of eel during downstream descend}

In total 107 of 121 migrating eel disappeared (88\%), of which 66 (55\%) eel between river section 1 after HPSII and the detection station at the sea (Figure 4 and Figure 5). In total 30 eel disappeared between HPSI and HPSII and 85 eel reached the first detection station downstream the HPSII - weir complex. Between the first and second river section after HPSII (at Capelse Veer), 41 eel disappeared, of which 32 eel disappeared between November 13 and 17 of 2010 (Figure 5). In total 14 eel (12\%) reached the final stations at the entrance of the North Sea. Accounting for misdetection ${ }^{1}$ this number is probably higher than 14 individuals.

\footnotetext{
${ }^{1}$ misdetection analysis: e.g. eel that were detected upstream at the HPS entrance and further downstream the complex, but missed the station directly downstream the HPS
} 


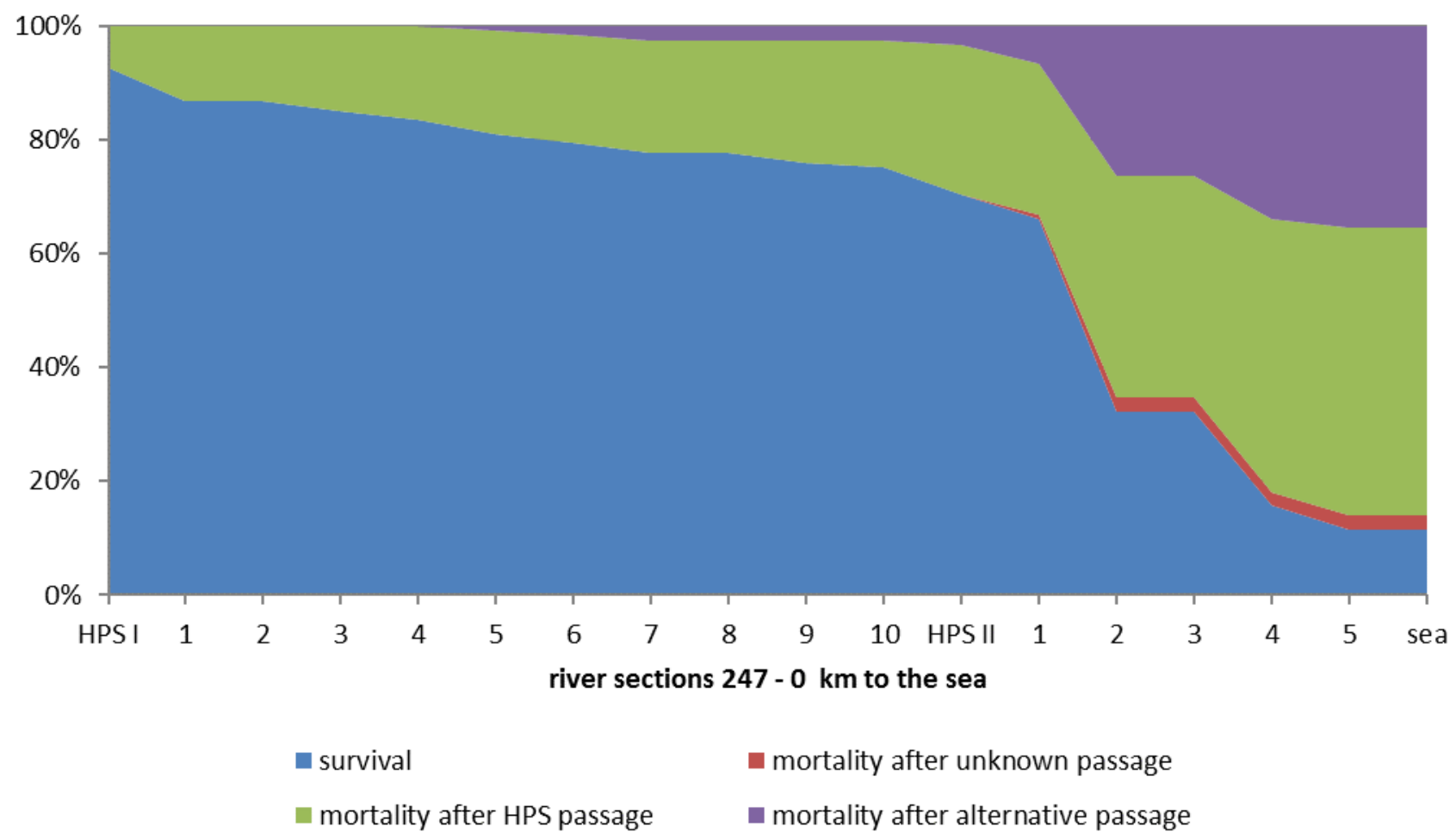

Figure 4. Disappearance of silver eel during their downstream migration. A strong decline of survival can be observed in the downstream area after HPS II. $12 \%(n=14)$ has reached the sea.

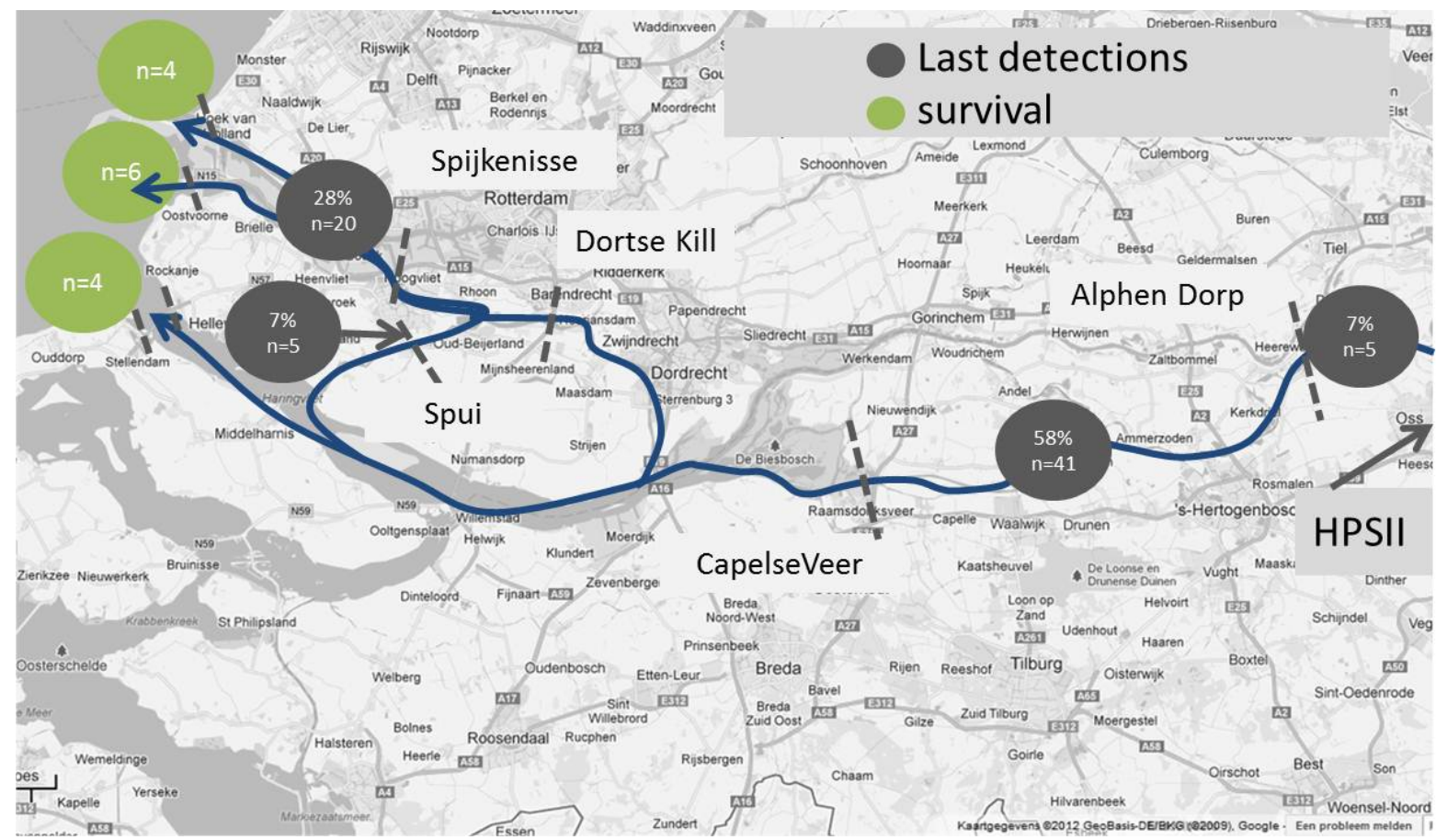

Figure 5. Disappearance of silver eel in the downstream section of the river. In total 71 eel that reached the area downstream from HPSII were never detected at the last four stations near the North Sea. 


\subsection{HPS mortality estimations}

\subsubsection{HPS-Mortality according to protocol cf 2002 and 2004}

In 2010, 133 eel (of which 121 further downstream) were detected at the entrances of the HP-stations. Of those 133 eel, $47 \%$ were detected more than twice at the entrance and were assumed to take an alternative route (correction factor $=0.47$, see material and methods). The maximum mortality estimation was estimated at $32 \mathrm{eel}$ (133 eel * 0.24). The minumum mortality estimation was estimated at 17 eel $(133 *(1-0.47) * 0.24)$. The total migrating batch was 121 eel which makes the mortality range at $14 \%-26 \%$ (Table 2 ).

\subsubsection{New mortality estimations}

From the 133 eel that were detected at the entrance of both HP stations, 112 eel actually passed both the HP-stations. After corrections for misdetections, this is possibly 125 eel (misdetection analysis: eel that were detected upstream at the HPS entrance and further downstream the complex, but missed the station directly downstream the HPS. This resulted in a range of $112-125$ eel that passed both HPstations. According to Bruijs et al. (2003) $24 \%$ of these eel will suffer from the turbines which are 27 30 individuals, which is $22-25 \%$ from the total migrating batch (Table 2 ). There were no reports of surgically implanted eel that were caught or found during the experimental period.

Table 2. Mortality calculations after three telemetry studies. In previous studies also mortality estimates for commercial and recreational fisheries were made. Commercial fisheries was not allowed in the current study period $(n=0)$ and no fish were reported in recreational fisheries $(n=0)$.

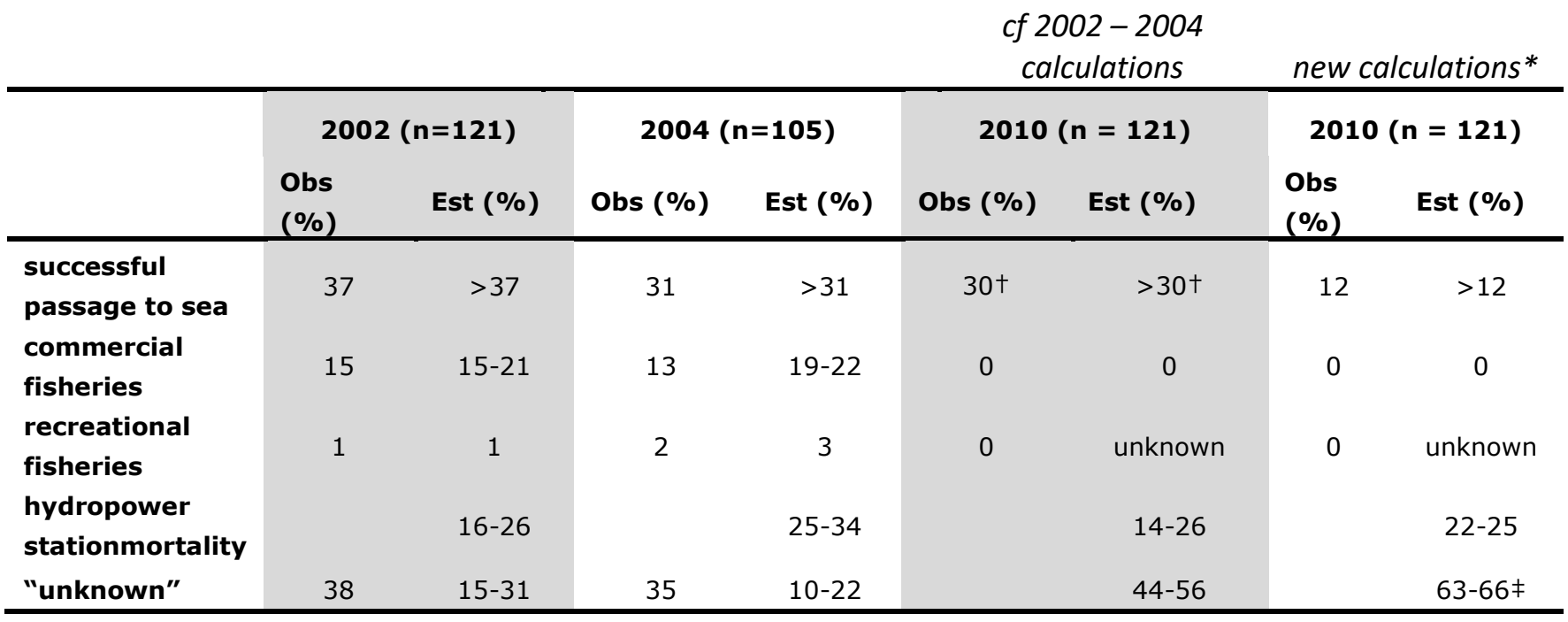

* Calculations based on more detailed migration information due to additional detection stations.

+ Reached downstream sections of the river ( $n=39$ see Fig 5 )

₹ Mainly unknown disappearance after HPSII in period 13 and 17 November 2010

\subsection{Indirect or delayed mortality}

In total $24(28.6 \%)$ eel 'disappeared' after passing through one of the HP-stations ('HPS eel') and 4 $(10.8 \%)$ 'disappeared' after using an alternative route. 84 eel passed both HP-stations, 37 passed using other routes (weir $n=18$, ship locks $n=17$ or fishway $n=2$ ). This is group 1 described in section 3.2.4. Of the reference group (group 2 described in section 3.2.4), 4 individuals 'disappeared' and will correct for mortality estimations other than caused by the HPS. The direct and delayed mortality was estimated at 20\%: 24 HPS eel / 84 HPS eel $* 100-4$ reference eel / 37 reference eel $* 100=17.8 \%$ delayed and direct mortality. 
The mortality rate of $17.8 \%$ is lower than (Bruijs et al. 2003) found in their study, which was expected since some eel may have died after passage in the last part of the river after section 10 (Figure 1). Those are not taken into account (section 3.2.4). New lethal injuries due to passage through HPSII could influence mortality estimates after passage through HPSI. The mortality estimation of $17.8 \%$ is therefore a minimum estimation for the Dutch section of the river Meuse. 


\section{$5 \quad$ Discussion and conclusions}

\subsection{HPS-mortality compared to mortality before fisheries ban?}

When the same protocols were used as used in previous studies with fewer detection stations than installed in 2010 (Winter et al. 2006), it was estimated that 30\% of the migrating eel reached the downstream section of the river near the North sea (Table 2). This percentage is approximately the same as in previous studies (Table 2). However, an analyses using the additional detection stations at the Haringvliet and Nieuwe Waterweg it was determined that only $12 \%$ of the migrating eel reached the North Sea. In conclusion, $30 \%$ of the migrating eel reached the downstream river area before reaching the North Sea $(12 \%)$.

In 2010 a higher percentage of eel reached HPSII (75\%) compared to the eel released in 2002 (61\%) and $2004(72 \%)$. Although this higher percentage reaching HPSII, 66 eel (55\% of the migrating eel in this study) disappeared after section 1 in the downstream area of HPSII (Figure 4). Even if there were fisheries activities allowed, 55\% mortality is much higher than the estimated fisheries mortality rates of 21 - 25\% in 2002 and 19 - 22\% in 2004 (Winter et al. 2007). In general there are two locations with high disappearance of eel: 1) The river section between Alphen Dorp (section 1) and Capelse Veer (section 2). The highest disappearance occurred in the period 13 to 17 November 2010. And 2) The river section after Spijkenisse (section 5). It is unknown why so many eel disappeared in the downstream area since fisheries activities were closed. Several explanations are described in sections 5.3 - some of them being more likely than the other.

According to mortality estimations for the HP-stations calculated with the protocol used in 2002 (16 $26 \%)$ and $2004(25-34 \%)$ there is no big difference in mortality estimations in $2010(14-26 \%)$. A comparison between a previous protocol for mortality estimations (14-26\%) and new mortality estimations using more detection station (22-25\%) suggested that a more precise mortality estimation must be found in the upper limits of the mortality ranges derived from previous studies.

\subsection{What is the delayed and direct mortality estimation of the migration batch?}

Minimum delayed mortality estimations was estimated at $17.8 \%$ of the migrations batch and was corrected for other factors causing mortality (e.g. natural mortality, disease, predation etc.). This is lower than the value found by Bruijs et al. (2003). It is likely that the estimation of a rate of $17.8 \%$ is actually an underestimation, since an eel can migrate $53 \mathrm{~km} /$ day (Verbiest et al. 2012) and can arrive within three days at HPSII after passage through HPSI. If an eel was lethally injured it might be possible that this particular eel died after passage at the HPSII - weir complex due to wounds sustained at HPSI. Therefore delayed mortality of $17.8 \%$ is thought to be an underestimation and in reality probably approaching the rate found by (Bruijs et al. 2003), namely $24 \%$.

1) Misdetection In the downstream sections the river is deeper and wider than the upper parts of the river Meuse. It could be possible that misdetection rate was higher compared to other parts of the river. This could be an explanation of the disappearance at the locations between Spijkenisse and the final stations at the entrance of the North Sea, since this area is deeper and wider than other parts of the river. If all of these eel disappeared were misdetected, than 20 eel may be added to the successful passage. In this case, $34(14+20)$ eel successfully passed to the sea, which is $28 \%$ of the total migrating batch. However the Nedap trail system functions 
well with a water depth of 15 metre and a passing speed of 5-6 m/s at maximum (Breukelaar et al. 1998). An exceptional high misdetection rate could explain a large fraction of the disappearance but there is technically no reason to assume that it does account for all the disappearance in all the downstream river sections.

2) Misdetection due to high water discharge $A$ large peak of water discharge occurred up to $1500 \mathrm{~m}^{3} / \mathrm{s}$ in the month November 2010. It could be possible that many eel migrated outside the detection zone of downstream stations when the river water spread over the river banks. Water discharge exponentially increased from $480 \mathrm{~m}^{3} / \mathrm{s}-1484 \mathrm{~m}^{3} / \mathrm{s}$ at 16 November to 470 $\mathrm{m}^{3} / \mathrm{s}$ at 20 November 2010. Many silver eel migrated during this large peak of water discharge and may be undetected due to migration over the flooded river banks. It is unknown if eel migrated out of the range of the detections stations. Misdetection due to passage over the river banks could explain an unknown fraction of the disappearance especially in the river sections directly downstream HPSII. However, based on earlier studies (Winter and Fredrich 2003, Winter et al. 2006, Jansen et al. 2007, Winter et al. 2007, Verbiest et al. 2012) there is no reason to assume that it does account for the majority of disappearance in all the downstream river sections, since there was no clear evidence that this phenomenon occured in this order of magnitude.

3) Poaching People with no fishing license and illegal fykes or other fishing activities. Since poaching is an illegal activity, return rate of the transponders was not expected and the amount of eel that suffered due to poaching was unknown. This activity could occur in all areas. If all the eel died due to poaching this would be $55 \%$ of the population which is unlikely since commercial fisheries mortality was estimated at $19-25 \%$ (2002 and 2004 combined, Table 2). It is unclear how efficient law enforcement was at the time this study was executed. It may be that poaching could explain a large fraction of the disappearance.

4) Mortality due to ship traffic The downstream river area has intensive ship traffic. It is thought from anecdotal stories and observations that eel could be damaged by the propeller of large ships. Dead eel were found in dry riverbanks with no HPS in the upstream river sections. Although they are anecdotal stories, the fact that migrating eel are swimming in the upper parts of the water column and are using the mainstream of the water for energetic efficiency reasons, it could be possible that some of the eel died due to intensive ship traffic. Mortality due to ship traffic could explain a fraction of the disappearance.

5) Recreational fisheries Each transponder has a clear sign of a reward ( $€ 30,-)$. There was no report of any recapture. Other studies (Schmalz et al. 2004, Winter et al. 2006) showed a return rate up to $60-70 \%$ with a lower reward. Since the return rate in 2002 and 2004 was estimated at $1-3 \%$ it may be that recreational fisheries could explain a small fraction of the disappearance. There is a catch and release obligation of eel caught in recreational fisheries since 2009.

6) Commercial fisheries Between 1 September 2010 and 30 November 2010 there was a closed period for commercial eel fisheries in the river Meuse. In this period professional fisherman were allowed to continue fishing on crab (Eriocheir sinensis) but with adapted fyke nets in which eel are able to escape. It may be that some eel unintentionally died due to crab fyke fishing, the fykes may be too full with crab or waste for escaping. Though it is unlikely that so many eel disappeared in the period 13 to 17 November 2010 due to this reason, since the fykes are specially adapted so that the majority of the eel can escape through the meshes of the fyke. It might be that commercial crab fisheries could explain a small fraction of the disappearance.

7) Natural mortality (e.g. diseases, predation, parasites) Winter et al. (2006) suggested that natural mortality might also accounted for unknown disappearance, however predation for such large silver eel (mean is $82.1 \mathrm{~cm}$ ) used in this study is very low and therefore unlikely to be the cause of such high number of disappearance. This is supported with the calculated mortality rate in the reference group used for delayed mortality estimation was estimated at $3.3 \%$ of the migrating population which is far lower than $55 \%$ of mortality in de downstream river sections.

8) Disease (waste discharge, weakening) There were no sings or indications that a certain disease or weakening due to for example waste water caused high mortality rates in the downstream area. There is no reason to assume that massive diseases does account for the majority of disappearance in all the downstream river sections, since there was no clear evidence that this phenomenon occured in this order of magnitude. 
9) Experimental mortality (Winter et al. 2006) suggested that it is unlikely that this factor accounts for a substantial part of the fraction of the disappeared eel.

10) Delayed migratory behaviour Other studies (Winter et al. 2006) suggested that there were reasons to assume that eel do delay their silvery phase and remain at a certain part of the river. The downstream river section are relatively near the North Sea and the migrating eel passed already several kilometres since they started their migration. The majority of the eel migrated within a couple of days to the North Sea and some delayed their migration period. Some of the implanted eel could have remained within the downstream river sections and turned back into a yellow phase. Winter et al. (2006) suggested that it is unlikely that this factor accounts for a substantial part of the fraction of the disappeared eel, especially since this kind of behaviour is more likely to occur in the upper sections of the river and not in the downstream sections of the river.

11) Passage through other routes (Oosterschelde or Grevelingenmeer) In total $4 \%$ of the migrating batch migrated directly through the ship locks at HPS I and $11 \%$, including returning behaviour, eventually passed through the ship locks. There is a possible escape route in the downstream area through ship locks and it possible that silver eel could have taken this route to lake Grevelingen and finally to the North Sea. There are no detection stations in the Grevelingen lake and if silver eel would have taken this route, they would disappear in section 3 after HPS II, while the majority already disappeared in the earlier section upstream. Some of the eel could have found their escape route through the ship locks entering the Grevelingen lake, however it is unlikely that this could explain a large fraction of the disappearance.

In general there is no logical reason found yet why so many eel disappeared in the downstream river sections. A large part of the described reasons above occurred simultaneously could explain the large losses of the migrating eel. 


\section{Quality Assurance}

Wageningen Marine Research utilises an ISO 9001:2015 certified quality management system. This certificate is valid until 15 December 2021. The organisation has been certified since 27 February 2001. The certification was issued by DNV GL.

Furthermore, the chemical laboratory at IJmuiden has EN-ISO/IEC 17025:2017 accreditation for test laboratories with number L097. This accreditation is valid until $1^{\text {th }}$ of April 2021 and was first issued on 27 March 1997. Accreditation was granted by the Council for Accreditation. The chemical laboratory at IJmuiden has thus demonstrated its ability to provide valid results according a technically competent manner and to work according to the ISO 17025 standard. The scope (L097) of de accredited analytical methods can be found at the website of the Council for Accreditation (www.rva.nl).

On the basis of this accreditation, the quality characteristic $Q$ is awarded to the results of those components which are incorporated in the scope, provided they comply with all quality requirements. The quality characteristic $Q$ is stated in the tables with the results. If, the quality characteristic $Q$ is not mentioned, the reason why is explained.

The quality of the test methods is ensured in various ways. The accuracy of the analysis is regularly assessed by participation in inter-laboratory performance studies including those organized by QUASIMEME. If no inter-laboratory study is available, a second-level control is performed. In addition, a first-level control is performed for each series of measurements.

In addition to the line controls the following general quality controls are carried out:

- Blank research.

- Recovery.

- Internal standard

- Injection standard.

- Sensitivity.

The above controls are described in Wageningen Marine Research working instruction ISW 2.10.2.105. If desired, information regarding the performance characteristics of the analytical methods is available at the chemical laboratory at IJmuiden.

If the quality cannot be guaranteed, appropriate measures are taken. 


\section{References}

Breukelaar, A. W., A. B. de Vaate, and K. T. W. Fockens. 1998. Inland migration study of sea trout (Salmo trutta) into the rivers Rhine and Meuse (The Netherlands), based on inductive coupling radio telemetry. Hydrobiologia 372:29-33.

Bruijs, M. C. M., H. J. G. Polman, G. H. F. M. van Aerssen, R. H. Hadderingh, H. V. Winter, C. Deerenberg, and H. M. Jansen. 2003. Management of silver eel: Human impact on downstream migrating eel in the river Meuse. EU Report Contract Q5RS-.

Dekker, W. 2000. Impact of yellow eel exploitation on spawner production in Lake IJsselmeer, the Netherlands. Dana 2000 12:17-32.

Dekker, W. 2004. Slipping through our hands: population dynamics of the European Eel. . PhD thesis. University of Amsterdam.

Hadderingh, R. H., and H. D. Bakker. 1998. Fish mortality due to passage through hydroelectric power stations on the Meuse and Vecht Rivers. Oxford, UK.

ICES. 2018. Report of the joint EIFAAC/ICES/GFCM working group on eels (WGEEL). ICES CM 2018/ACOM:15. $152 \mathrm{pp}$.

Jansen, H. M., H. V. Winter, M. C. M. Bruijs, and H. J. G. Polman. 2007. Just go with the flow? Route selection and mortality during downstream migration of silver eels in relation to river discharge. Ices Journal of Marine Science 64:1437-1443.

Schmalz, P. J., M. J. Hansen, M. E. Holey, P. C. McKee, and M. L. Toneys. 2004. Effect of Rewards on Lake Trout Tag Returns in Northwestern Lake Michigan. North American Journal of Fisheries Management 24:1-6.

Verbiest, H., A. Breukelaar, M. Ovidio, J.-C. Philippart, and C. Belpaire. 2012. Escapement success and patterns of downstream migration of female silver eel Anguilla anguilla in the River Meuse. Ecology of Freshwater Fish 21:395-403.

Winter, H. V., and F. Fredrich. 2003. Migratory behaviour of ide: a comparison between the lowland rivers Elbe, Germany, and Vecht, The Netherlands. Journal of Fish Biology 63:871-880.

Winter, H. V., H. M. Jansen, and A. Breukelaar. 2007. Silver eel mortality during downstream migration in the River Meuse, from a population perspective. Ices Journal of Marine Science 64:1444-1449.

Winter, H. V., H. M. Jansen, and M. C. M. Bruijs. 2006. Assessing the impact of hydropower and fisheries on downstream migrating silver eel, Anguilla anguilla, by telemetry in the River Meuse. Ecology of Freshwater Fish 15:221-228. 


\section{Justification}

Report C099/19

Project Number: 4311218545

The scientific quality of this report has been peer reviewed by a colleague scientist and a member of the Management Team of Wageningen Marine Research

Approved: $\quad$ Dr. T. van der Hammen

Researcher

Signature:

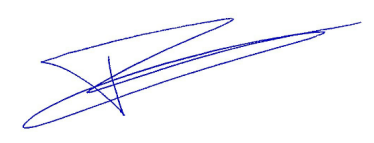

Date:

18 November, 2019

Approved: $\quad$ Drs. J. Asjes

Manager Integration

Signature:

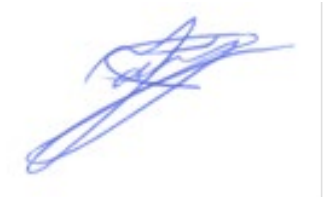

Date:

18 November, 2019 
Wageningen Marine Research

T +31(0)317480900

E: marine-research@wur.nl

www.wur.eu/marine-research

Visitors' address

- Ankerpark 271781 AG Den Helder

- Korringaweg 7, 4401 NT Yerseke

- Haringkade 1, 1976 CP IJmuiden
With knowledge, independent scientific research and advice, Wageningen Marine Research substantially contributes to more sustainable and more careful management, use and protection of natural riches in marine, coastal and freshwater areas.

Wageningen Marine Research is part of Wageningen University \& Research. Wageningen University \& Research is the collaboration between Wageningen University and the Wageningen Research Foundation and its mission is: 'To explore the potential for improving the quality of life' 